\title{
Personality profiles of divers: integrating results across studies
}

\section{Charles H. Van Wijk}

Stellenbosch University, Faculty of Medicine and Health Sciences, Cape Town, South Africa

\begin{abstract}
Background: There are numerous reports on diver personality, spanning across five decades, across national boundaries, and using a range of measures to describe diver profiles. However, the range of reports poses challenges to interpreting new studies, particularly when having to compare findings across generations, measurements, and national/cultural contexts. This paper aimed to review and integrate diver personality descriptions, drawing on the available studies that reported trait theory based data for naval and sport divers. Materials and methods: Available studies on diver personality - associated with trait theory - were tabulated and the specific traits associated with divers described. Their findings were then integrated into a synthesised description of personality traits.

Results: The results suggest remarkably stable military diver profiles across generations, measures, and navies, with some unique differences observed due to national-cultural variables. It was of particular interest that different measures of personality appeared to present related constructions of diver profiles. Navy divers share, among others, a propensity for adventurousness, a strong sense of self-agency, and low trait anxiety. Unsurprisingly, personality profiling could not be generalised across military-civilian diving contexts, and the same clear profile differentiation of navy divers was not visible among sport divers.

Conclusions: Contemporary local data - in the context of military diving - could productively be compared to the body of existing reports, at least where similar theoretical models are used.
\end{abstract}

(Int Marit Health 2018; 69, 4: 297-303)

Key words: personality measurement, profiling, navy divers, sport divers

\section{INTRODUCTION}

\section{BACKGROUND}

Personality - as human factor in extreme environments - remains of enduring interest. In the underwater context, personality studies have a rich history, and a survey of the available literature provides a number of psychological descriptions, in particular of navy divers, crossing generations, national borders, and certain operational contexts.

These studies can often be interpreted from a common theoretical viewpoint, as most of them are based on trait theory models. Trait theory views human nature from a perspective of consistent and enduring individual differences, and personality traits are defined as characteristic ways of behaving [1]. Using this framework, any individual could be placed somewhere on the continuum of any given trait.

In spite of some theoretical common ground between studies on the personality of divers, both the temporal and geographic range of these reports pose, among others, three challenges to the interpretation and comparison of new studies. They are the challenges of generational, measurement, and cultural equivalence.

\section{GENERATIONAL CHALLENGES}

With studies spanning five decades ( \pm 1970-2018), the extent to which findings can be generalised across time may be questioned (e.g. can findings from different decades be compared?). For example, historical contexts (war, conscription, nationalism, etc.) may all have influenced the recruitment of navy divers in the past, even as 
socio-economic factors may do the same at present. In the recreational sphere, the popularisation of sport diving would potentially allow a wide range of personalities to participate, while the development of engineering technologies may have changed the demands on divers, potentially requiring a different personal profile to attain and maintain good psychological adaptation under water.

\section{MEASUREMENT CHALLENGES}

The measurement of personality poses two challenges to the comparison of results. This refers to the development of personality theory, and the development of measuring instruments (psychometry), over time. In this regard, earlier reports used older measures. Those studies used the prevailing theoretical models of the time. For example, Cattell's trait theory, which organised personality traits into 16 dimensions of human personality (known as the 16PF), was used extensively in the personality profiling of divers. This was supplemented by a consistent use of additional personality traits, such as Zuckerman's Sensation Seeking, or Rotter's Locus of Control, to further profile the personality of divers.

In contemporary psychology, the Five Factor Model (FFM) has emerged as the dominant framework for studying personality [2, 3]. The FFM is based on the observation that human personality traits can be reduced to five factors (sometimes referred to as the Big Five), and that all other traits fit within these five factors [4]. Recent studies have used the FFM to describe diver profiles, and as most of the instruments used to measure the Big Five were related (based on Costa and McCrae's 'International Personality Item Pool'; IPIP), their outcomes are generally comparable.

\section{NATIONAL/CULTURAL CHALLENGES}

Most of the older studies on diver personality emanated from the global north. World region has a significant effect on psychometric scale scores, for example on Big Five personality scales $[5,6]$, where smaller standard deviations are found in African samples (i.e. more homogenous expression of Big Five factors). Apart from region, culture further influences the development of personalities, with some culture-specific aspects corresponding to cultural syndromes such as complexity, tightness, individualism, and collectivism [7, 8]. Individualism is generally used to describe the predominant cultures of Western Europe, North America, Australia and New Zealand. In contrast, African, Middle Eastern and East Asian countries are characterised primarily by collectivism [8]. The reported differences in personality descriptions between so-called 'Western', and 'African', or 'Asian' samples open the possibility of different personality profiles between divers from different regions. Indeed, differences in country-specific navy diver samples have already been observed [9]. This leads to the challenge of generalising findings across national boundaries (e.g. can findings from studies from different navies be compared?).

\section{AIM}

The range of studies describing diver personality traits, spanning across generations, countries, and measuring instruments, raised questions about the extent to which contemporary local data (whichever the locale) can be compared to the array of existing available reports (i.e. can results be generalised across studies?). This paper therefore aims to review and integrate diver personality descriptions, drawing on the available studies that reported trait theory based data for military and sport divers.

\section{MATERIALS AND METHODS}

\section{DATA COLLECTION}

The available studies on diver personality for which sufficient data could be obtained (including full reference, sample type, psychometric measures, and main findings) were included in this analysis. Only studies associated with trait theory, and available in English, were used. All the studies were in the public domain, and came from published academic papers or chapters from books, from technical reports, or from conference posters.

As mentioned, several studies reporting comprehensive profiling of diver personalities used derivatives of Cattell's 16PF model [10-17], and results can validly be compared using the 16PF trait-letters. Where studies used measures based on different models [18], easy synthesis across reports remains elusive [19].

Other studies exploring specific individual personality traits often used the same measures, allowing for direct comparisons across studies. Examples include Rotter's Internality-externality Scale [10, 16, 20] and Zuckerman's Sensation Seeking Scale [11, 20-22].

There are also a number of studies available that reported personality functioning of navy diver samples from a mental health perspective, using the Minnesota Multiphasic Personality Inventory (MMPI) [23-28]. They all appear to report similar findings, namely a generally positive mental health profile among divers across various navies, with specific and consistent outliers across the studies [27]. MMPI studies were excluded from the current analysis.

Fewer studies used the FFM, are all more recent, and are mostly in the sport diver domain [29-31]. While they employed an array of instruments, all were based on the IPIP, and their outcomes thus comparable.

\section{DATA ANALYSIS}

The personality studies were tabulated and the specific traits associated with divers described (Table 1). This was 
Table 1. Selected reports on diver personality profiling

\begin{tabular}{|c|c|c|c|c|c|}
\hline Serial & Authors, year & Sample & Traits/factors & $\begin{array}{l}\text { Psychometric } \\
\text { measures }\end{array}$ & Summary of main findings \\
\hline 1 & $\begin{array}{l}\text { Biersner and } \\
\text { Cameron, } 1970 \text { [23] }\end{array}$ & Navy & $\begin{array}{l}\text { Comprehensive personality scale } \\
\text { Risk taking }\end{array}$ & $\begin{array}{l}\text { EPPS } \\
\text { Betting game }\end{array}$ & $\begin{array}{l}\text { Higher masculinity } \\
\text { Lesser socialisation } \\
\text { Greater aggressiveness } \\
\text { Greater risk taking }\end{array}$ \\
\hline 2 & Biersner, 1973 [32] & Navy & Behavioural history & History & $\begin{array}{l}\text { More traffic violations and } \\
\text { more arrests }\end{array}$ \\
\hline 3 & $\begin{array}{l}\text { Biersner and Larocco, } \\
1983 \text { [10] } \\
\text { Biersner and Larocco, } \\
1987 \text { [11] }\end{array}$ & Navy & $\begin{array}{l}\text { Specific traits: } \\
\text { - locus of control } \\
\text { - socialisation scale } \\
\text { - trait anxiety } \\
\text { - sensation seeking }\end{array}$ & $\begin{array}{l}\text { RIES } \\
\text { CPI } \\
\text { STAI } \\
\text { SSS }\end{array}$ & $\begin{array}{l}\text { Greater internality } \\
\text { Lesser socialisation } \\
\text { Lower trait anxiety } \\
\text { Seek physical adventure/ } \\
\text { risks, rather than simply novel } \\
\text { experiences }\end{array}$ \\
\hline 4 & $\begin{array}{l}\text { Beckman et al., } \\
1996[18]\end{array}$ & Navy & Comprehensive personality scale & MIPS & $\begin{array}{l}\text { Optimistic } \\
\text { Independent } \\
\text { Self-serving } \\
\text { Analytical } \\
\text { Tend towards social } \\
\text { aggressiveness }\end{array}$ \\
\hline 5 & $\begin{array}{l}\text { Van Wijk and Waters, } \\
2001[17]\end{array}$ & Navy & Comprehensive personality scale & $16 \mathrm{PF}$ & $\begin{array}{l}\text { Enthusiasm: } \mathrm{F}^{+} \\
\text {Adventurousness: } \mathrm{H}^{+} \\
\text {Confidence: } \mathrm{O}^{-} \\
\text {Group orientation: } \mathrm{Q}^{-}\end{array}$ \\
\hline 6 & $\begin{array}{l}\text { Van Wijk, } 2007,2008, \\
2014[16,22,33]\end{array}$ & Navy & $\begin{array}{l}\text { Specific traits: } \\
\text { - sensation seeking } \\
\text { - locus of control } \\
\text { - trait anxiety } \\
\text { Comprehensive personality scale }\end{array}$ & $\begin{array}{l}\text { SSS-V } \\
\text { RIES } \\
\text { STPI } \\
16 P F\end{array}$ & $\begin{array}{l}\text { High TAS, low DI and BS } \\
\text { Greater internality } \\
\text { Lower trait anxiety } \\
\text { Enthusiasm: } \mathrm{F}^{+} \\
\text {Adventurousness: } \mathrm{H}^{+} \\
\text {Confidence: } 0^{-} \\
\text {Low anxiety: } \mathrm{Q4}^{-}\end{array}$ \\
\hline 7 & $\begin{array}{l}\text { Colodro-Plaza et al., } \\
2014,2015[13,14]\end{array}$ & Navy & $\begin{array}{l}\text { Comprehensive personality scale } \\
\text { Anxiety }\end{array}$ & $\begin{array}{l}\text { 16PF } \\
\text { FIA }\end{array}$ & $\begin{array}{l}\text { Emotional stability: } \mathrm{C}^{+} \\
\text {Self-control: } \mathrm{Q3}^{+} \\
\text {Low: } \\
\text { - sensitivity: } \text { I- }^{-} \\
\text {- apprehension: } 0^{-} \\
\text {- tension: } \mathrm{Q4}^{-}\end{array}$ \\
\hline 8 & $\begin{array}{l}\text { Shopov and Vazharov, } \\
2017 \text { [15] }\end{array}$ & Navy & Comprehensive personality scale & $16 \mathrm{PF}$ & $\begin{array}{l}\text { Enthusiasm: } \mathrm{F}^{+} \\
\text {Adventurousness: } \mathrm{H}^{+} \\
\text {Confidence: } \mathrm{O}^{-} \\
\text {Group orientation: } \mathrm{Q}^{-}\end{array}$ \\
\hline 9 & Van Wijk, 2018 [34] & Navy & "Big Five" & $\mathrm{BFI}-44$ & $\begin{array}{l}\text { Agreeableness: } \mathrm{A}^{+} \\
\text {Conscientiousness: } \mathrm{C}^{+} \\
\text {Neuroticism: } \mathrm{N}^{-}\end{array}$ \\
\hline 10 & $\begin{array}{l}\text { Martin and Myrick, } \\
1976 \text { [35] }\end{array}$ & $\begin{array}{l}\text { Sport } \\
\text { divers }\end{array}$ & Comprehensive personality scale & VPQ & $\begin{array}{l}\text { Socially aggressive } \\
\text { Low anxiety }\end{array}$ \\
\hline 11 & $\begin{array}{l}\text { Griffiths et al., } \\
1978 \text { [36] }\end{array}$ & $\begin{array}{l}\text { Sport } \\
\text { divers }\end{array}$ & $\begin{array}{l}\text { Specific trait: } \\
\text { - trait anxiety }\end{array}$ & STAI & Lower trait anxiety \\
\hline 12 & $\begin{array}{l}\text { Heyman and Rose, } \\
1980 \text { [20] }\end{array}$ & $\begin{array}{l}\text { Sport } \\
\text { divers }\end{array}$ & $\begin{array}{l}\text { Specific traits: } \\
\text { - locus of control } \\
\text { - trait anxiety } \\
\text { - sensation seeking } \\
\text { - masculinity }\end{array}$ & $\begin{array}{l}\text { RIES } \\
\text { STAI (T-Ax) } \\
\text { SSS-V } \\
\text { BSRI }\end{array}$ & $\begin{array}{l}\text { Both men and women: } \\
\text { Greater internality } \\
\text { Lower trait anxiety } \\
\text { More sensation seeking } \\
\text { Higher masculinity }\end{array}$ \\
\hline
\end{tabular}


Table 1 (cont.). Selected reports on diver personality profiling

\begin{tabular}{|c|c|c|c|c|c|}
\hline Serial & Authors, year & Sample & Traits/factors & $\begin{array}{l}\text { Psychometric } \\
\text { measures }\end{array}$ & Summary of main findings \\
\hline 13 & $\begin{array}{l}\text { Taylor et al., } \\
2001[21]\end{array}$ & $\begin{array}{l}\text { Sport } \\
\text { divers }\end{array}$ & $\begin{array}{l}\text { Specific trait: } \\
\text { - sensation seeking }\end{array}$ & SSS-V & $\begin{array}{l}\text { High TAS and ES, low DI (with } \\
\text { total similar to reference group) }\end{array}$ \\
\hline 14 & Van Wijk, 2002 [37] & $\begin{array}{l}\text { Sport } \\
\text { divers }\end{array}$ & Comprehensive personality scale & 16PF & $\begin{array}{l}\text { Enthusiasm: } \mathrm{F}^{+} \\
\text {Adventurousness: } \mathrm{H}^{+} \\
\text {Confidence: } \mathrm{O}^{-} \\
\text {Other factors were } \\
\text { undifferentiated }\end{array}$ \\
\hline 15 & Coetzee, 2010 [12] & $\begin{array}{l}\text { Sport } \\
\text { divers }\end{array}$ & Comprehensive personality scale & CAQ & $\begin{array}{l}\text { Boldness: } \mathrm{H}^{+} \\
\text {Self-sufficiency: } \mathrm{Q}^{+} \\
\text {Suspiciousness: } \mathrm{L}^{+} \\
\text {Tension: } \mathrm{Q4}^{+} \\
\text {Low: } \\
\text { - warmth: } \mathrm{A}^{-} \\
\text {- emotional stability: } \mathrm{C}^{-} \\
\text {- conformity: } \mathrm{G}^{-} \\
\text {- sensitivity: } \mathrm{I}^{-}\end{array}$ \\
\hline 16 & $\begin{array}{l}\text { Musa et al., } \\
2010 \text { [29] }\end{array}$ & $\begin{array}{l}\text { Tourist } \\
\text { divers }\end{array}$ & Big Five & NEO-FFI & $\begin{array}{l}\text { Agreeableness: } \mathrm{A}^{+} \\
\text {Conscientiousness: } \mathrm{C}^{+}\end{array}$ \\
\hline 17 & $\begin{array}{l}\text { Ong and Musa, } \\
2012[30]\end{array}$ & $\begin{array}{l}\text { Tourist } \\
\text { divers }\end{array}$ & Big Five & NEO-PI-R & $\begin{array}{l}\text { Extraversion (NS): } \mathrm{E}^{+} \\
\text {Agreeableness (NS): } \mathrm{A}^{+} \\
\text {Openness to experience: } 0-\mathrm{E}^{+}\end{array}$ \\
\hline 18 & $\begin{array}{l}\text { Shopov and Vazharov, } \\
2017 \text { [15] }\end{array}$ & $\begin{array}{l}\text { Sport } \\
\text { divers }\end{array}$ & Comprehensive personality scale & $16 \mathrm{PF}$ & $\begin{array}{l}\text { Dominance: } \mathrm{E}^{+} \\
\text {Other factors were } \\
\text { undifferentiated }\end{array}$ \\
\hline 19 & Van Wijk, 2018 [31] & $\begin{array}{l}\text { Tourist } \\
\text { divers }\end{array}$ & Big Five & BFI-44 & $\begin{array}{l}\text { Agreeableness (NS): } \mathrm{A}^{+} \\
\text {Conscientious (NS): } \mathrm{C}^{+}\end{array}$ \\
\hline
\end{tabular}

Serial 10, 11, 12, 14 were university students; EPPS - Edwards Personal Preference Schedule; RIES - Rotter's Internality-Externality Scale; CPI - California Personality Inventory; STAI - State-Trait Anxiety Inventory; SSS - Sensation Seeking Scale; MIPS - Millon Index of Personality Styles; $16 P F$ - 16 Personality Factor Questionnaire; STPI - State-Trait Personality Inventory; FIA - Facilitating and Inhibiting Anxiety questionnaire; VPQ - Veldman Parker Questionnaire; BSRI - Bem Sex Role Inventory; CAQ - Clinical Analysis Questionnaire; NEO-FFI - NEO Five-Factor Inventory; NEO-PI-R - NEO Personality Inventory-Revised; BFI-44 - Big Five Inventory-44; NS - not significant; TAS - Thrill and Adventure Seeking; DI - Disinhibitions; BS - Boredom Susceptibility; ES - Experience Seeking

done separately for military and for sport divers. As could be expected, fewer studies were available for sport divers, possibly because the number of certified sport divers is larger and their personality profile therefore less homogenous. The table was used to develop an integrated personality description of divers.

\section{RESULTS}

Drawing on the studies collected in Table 1 (the references below are Table 1 serial numbers), there appear to be general consensus that military divers share the following traits:

(a) A propensity for sensation seeking, adventurousness, and associated risk-taking (serial 1, 2, 3, 5, 6, 8);

(b) A strong sense of self-agency (also referred to as internality, dispositional confidence) (serial 3, 4, 5, 6, 7, 8);

(c) Low trait anxiety (serial 3, 6, 7); and

(d) Enthusiasm and optimism (serial 4, 5, 6, 8).

These shared traits appear to hold stable across time ( \pm 1970-2015) and across different navies, e.g. United States Navy (USN), South African Navy (SAN), Spanish Navy, and Bulgarian Navy.
Further, most USN studies suggest lesser socialisation (serial 1, 3, 4), although this was not found among Spanish or Bulgarian Navy divers (serial 7,8), and even contrasted by particularly good social cooperation expressed among SAN divers (serial 5). Other differences in the reports of military divers appear to stem from methodological differences rather than referring to personality differences across samples.

The only study using FFM data with military divers reported higher scores for agreeableness and conscientiousness, and lower scores for neuroticism (serial 9). The highly differentiated and homogenised profile was particularly noteworthy.

For sport divers, there appear to be general consensus regarding:

(a) A propensity for sensation seeking, adventurousness, and associated risk-taking (serial 12, 13, 14, 15); and

(b) Somewhat lesser socialisation (serial 10, 15).

There are further some indications of lower trait anxiety (serial 10,11,12), but this is not universally supported (serial $15)$, and there are also alternative views suggesting population normative trait anxiety among non-professional divers $[38,39]$. Other differences in personality descriptions may 
indicate limitations to comparisons across civilian sport diver samples, rather than actual personality differences. It is noteworthy that a number of studies using comprehensive scales reported relatively undifferentiated profiles (serial 14, 18).

Recent studies using FFM data with sport divers suggest limited consistency in profile differentiation across the factors (serial 16,17,19), providing support for the idea that there generally is little differentiation in their profiles. The most consistent finding is that of possibly somewhat higher Agreeableness (serial 16, 17, 19), and given that sport diving is often a group activity, is therefore not surprising.

There were only two studies that directly compared navy and sport divers [15, 37], and both found a range of significant differences on their 16PF group profiles.

\section{DISCUSSION}

The personality profiles of military divers - using trait theory - appear surprisingly consistent across both generational and cultural contexts, as well as across different (but theoretically related) measures. While there is little evidence of personality's predictive value for selection purposes [40], the consistent profile is noteworthy in that it may reflect a response to environmental demands, and could thus be seen as supportive of personality-as-coping theories [41].

Using the Big Five, the SAN profile was clearly differentiated and highly homogenised (and far more homogenous than the sport diver samples using similar measures [29-31]). Unfortunately, the data is not able to answer the question of whether this homogenisation was reflective of a) navy diver selection influences, or b) any specific personality profile associated with this specialised environment, or c) local culture, in that previous studies found African samples to express homogenised scores on FFM measures [6], or d) other socialisation or adaptation dynamics.

It is noteworthy that low trait anxiety (also referred to as generalised anxiety or neuroticism) is consistently reported in navy diver samples, which leads to the question whether this reflects environmental requirements, or whether it is a function of selection (often required for military diving training), as the same findings are present in some sport diver samples, but not in others. There is a further interesting apparent contrast between the SAN and South African sport diver samples on anxiety (serial 6, 9 vs. 15), although this may simply reflect sample composition (e.g. experienced navy divers vs. entry level sport divers).

There was no strong profile differentiation for sport divers, and efforts to profile sport divers are probably unproductive given the range of individuals who enter diving as a sport. While low trait anxiety was consistently emphasised in almost all the military diver studies, the construct appears to be of lesser importance in the sport diving environment. However, given the reported association of elevated trait anxiety with panic proneness [42], this observation from recreational diving requires further consideration.

One exception to an otherwise consistent profile across navy samples is the divergent reports on constructs of social or group orientation (also referred to as socialisation or agreeableness). USN samples suggest lesser social cooperation, whereas SAN samples report good social integration, with European samples in between. The SAN profile is not unexpected, as social components in the SAN diving context have been described previously [43]. The divergent profiles may partly be due to individual navy settings (e.g. practical contexts). For example, SAN divers not only train and work in small teams with great emphasis on social cooperation; but as the diving branch is small, they also work with the same group for their whole career. Their profile may thus be the result of the socialisation into that specific operational environment. Further to the practical context, the divergent profiles may also reflect cultural presentations. As reviewed earlier, Individualism is generally associated with the dominant cultures of North America, while African cultures are often characterised primarily by Collectivism [8]. The consistency of the reports across time suggests that this is probably not a generational issue, but rather a cultural one.

There are a number of limitations to this analysis. The geographical range of the studies were limited, and reports from elsewhere in the world, also in different languages, may need to be consulted to gain a full understanding of the consistency of reported profiles. Further, diving contexts, particularly for the military samples, were not incorporated. In this regard the type of diving (e.g. combat diving, deep sea clearance diving, rescue and recovery diving, etc.) may influence the desirability of any particular personality trait or profile.

Personality descriptions, while academically interesting, may have limited practical application. Future research needs to extend personality studies from being descriptive, to associating profiles with behavioural markers, for example safety behaviour, injury risk, and psychological adaptation, to optimise the practical value of personality assessment.

\section{CONCLUSIONS}

Military diver profiling appears remarkably stable across generations, measures, and navies, with some unique differences due to national/cultural variables. It was of particular interest that different measures of personality appeared to present related constructions of diver profiles. Unsurprisingly, personality profiling could not be generalised across military-civilian diving contexts, and the same clear profile differentiation of navy divers was not visible among sport 
divers. In conclusion, the analysis suggests that contemporary local data - in the context of navy diving - could productively be compared to the body of existing reports, at least where similar theoretical models are used.

\section{REFERENCES}

1. APA. Personality [internet]. 2017. Available from . http://www.apa. org/topics/personality/ (cited 2018 September 10).

2. Digman JM. Personality Structure: Emergence of the Five-Factor Model. Annu Rev Psychol. 1990; 41(1): 417-440, doi: 10.1146/ annurev.ps.41.020190.002221.

3. McCrae RR, Costa PTJ. The five-factor theory of personality. In: John OP, Robins RW, Pervin LA, editors. Handbook of personality: Theory and research (3rd ed). Guilford Press, New York, NY 2008: 159-181.

4. John OP, Naumann LP, Soto CJ. Paradigm shift to the integrative Big Five trait taxonomy: History, measurement, and conceptual issues. In:, Robins RW, Pervin LA, editors. Handbook of personality: Theory and research (3rd ed). Guilford Press, New York, NY 2008: 114-158.

5. Allik J, McCrae R. Toward a geography of personality traits. J Cross-Cultural Psychol. 2016; 35(1): 13-28, doi: 10.1177/ 0022022103260382.

6. Schmitt D, Allik J, McCrae R, et al. The geographic distribution of big five personality traits. J Cross-Cultural Psychol. 2016; 38(2): 173-212, doi: 10.1177/0022022106297299.

7. Triandis HC, Suh EM. Cultural influences on personality. Annu Rev Psychol. 2002; 53: 133-160, doi: 10.1146/annurev. psych.53.100901.135200, indexed in Pubmed: 11752482.

8. Vogt L, Laher S. The five factor model of personality and individualism / collectivism in South Africa: an exploratory study. Psychology in Society. 2009; 37: 39-54.

9. Picano JJ, Williams TJ, Roland RR. Assessment and selection of high-risk operational personnel. In: Kennedy $\mathrm{CH}$, Zillmer EA, editors. Military Psychology. Guilford Press, New York, NY 2006: 353-370.

10. Biersner R, La Rocco J. Personality characteristics of US Navy divers. J Occup Organ Psychol. 2011; 56(4): 329-334, doi: 10.1111/ j.2044-8325.1983.tb00139.x.

11. Biersner RJ, Larocco JM. Personality and demographic variables related to individual responsiveness to diving stress. Undersea Biomed Res. 1987; 14(1): 67-73, indexed in Pubmed: 3810994.

12. Coetzee N. Personality profiles of recreational scuba divers. Afr J Phys Health Educ Recreat Dance. 2013; 16(4): 568-579, doi: 10.4314/ajpherd.v16i4.63416.

13. Colodro Plaza J, Garcés de los Fayos Ruiz EJ, López García JJ, et al. Prediction of human adaptation and performance in underwater environments. Psicothema. 2014; 26(3): 336-342, doi: 10.7334/ psicothema2014.5, indexed in Pubmed: 25069552.

14. Colodro J, Garcés-de-Los-Fayos EJ, López-García JJ, et al. Incremental validity of personality measures in predicting underwater performance and adaptation. Span J Psychol. 2015; 18: E15, doi: 10.1017/ s.p.2015.16, indexed in Pubmed: 26055931.

15. Shopov N, Vazharov I. Assessment of personality traits of navy divers. International Journal of Latest Research in Science and Technology. 2017; 6(2): 20-24.

16. Van Wijk C. The resilience of naval specialists: their sense of coherence and its relationship with measures of personality. S Afr J Psychol. 2008; 38(4): 737-751, doi: 10.1177/008124630803800412.

17. Van Wijk C, Waters AH. Personality characteristics of South African navy divers. Undersea Hyperb Med. 2001; 28(1): 25-30, indexed in Pubmed: 11732881.
18. Beckman TJ, Lall R, Johnson WB. Salient personality characteristics among Navy divers. Mil Med. 1996; 161(12): 717-719, indexed in Pubmed: 8990825.

19. Beckman TJ. Personality characteristics of South African navy divers. Undersea Hyperb Med. 2001; 28(4): 233-234, indexed in Pubmed: 12153152.

20. Heyman SR, Rose KG. Psychological variables affecting SCUBA performance. In: Nadeau CA, Halliwell WR, Newell KM, Roberts GC, editors. Psychology of motor behaviour and sport. Champaign, III. Human Kinetics 1980: 181-188.

21. Taylor DM, O'Toole KS, Auble TE, et al. Sensation seeking personality traits of recreational divers. SPUMS J. 2001; 31: 25-28.

22. Van Wijk, $\mathrm{CH}$. Sensation-seeking personality traits of navy divers. Diving Hyperb Med. 2007; 37: 10-15.

23. Biersner RJ, Cameron BJ. Betting preferences and personality characteristics of Navy divers. Aerosp Med. 1970; 41(11): 1289-1291, indexed in Pubmed: 4395236.

24. Dembert ML, Mooney LW, Ostfeld AM, et al. Multiphasic health profiles of Navy divers. Undersea Biomed Res. 1983; 10(1): 45-61, indexed in Pubmed: 6603041.

25. El Sheshai A, Rashed S, Sadek M. Psychiatric and psychometric study among divers. Egypt J Psychiatry. 1994; 17: 87-93.

26. Tansy WA. The longitudinal health study: a multiphasic medical surveillance program for US Navy submarines and diving personnel. Groton, CT: Naval Submarine Medical Research Laboratory; 1974. Report No. 786. Available from:. http://archive.rubicon-foundation. org/8814 (cited 2018 September 10).

27. Van Wijk C, Meintjes WAJ. Mental Health and Personality Functioning of Naval Specialists Working in Extreme Environments. Military Psychology. 2018; 29(6): 601-614, doi: 10.1037/ mil0000185.

28. Weybrew BB. Psychological screening of divers as subjects for long duration saturation experimentation. Groton, CT: Naval Submarine Medical Research Laboratory; 1974. Report no. 776. Available from: http://archive.rubiconfoundation.org/8804 (cited 2018 September 10).

29. Musa G, Seng W, Thirumoorthi T, et al. The Influence of Scuba Divers' Personality, Experience, and Demographic Profile on their Underwater Behavior. Tourism in Marine Environments. 2011; 7(1): 1-14, doi: $10.3727 / 154427310 \times 12826772784757$.

30. Ong TF, Musa G. Examining the influences of experience, personality and attitude on SCUBA divers' underwater behaviour: A structural equation model. Tourism Management. 2012; 33(6): 1521-1534, doi: 10.1016/j.tourman.2012.02.007.

31. Van Wijk C. Associations of personality and underwater behaviour among sport divers: A pilot study. Poster presented at the 2nd Tricontinental Conference on Diving and Hyperbaric Medicine; 2018 September 23-29; Durban, South Africa 2018.

32. Biersner RJ. Social development of naval divers. Aerosp Med. 1973; 44(7): 761-763.

33. Van Wijk CH. The use of Spielberger's State-Trait Personality Inventory (trait anxiety subscale) with naval subaquatic specialists. Int J Occup Med Environ Health. 2014; 27(6): 959-966, doi: 10.2478/s13382-014-0321-5, indexed in Pubmed: 25503890.

34. Van Wijk CH. Personality and Adaptation: Associations in a sample of experienced navy divers. Poster presented at the 2nd Tricontinental Conference on Diving and Hyperbaric Medicine; 2018 September 23-29; Durban, South Africa 2018.

35. Martin W, Myrick F. Personality and leisure time activities. Research Quarterly. American Alliance for Health, Physical Education and 
Recreation. 2013; 47(2): 246-253, doi: 10.1080/10671315.19 76.10615368.

36. Griffiths TJ, Steel DH, Vaccaro P. Anxiety levels of beginning Scuba students. Percept Mot Skills. 1978; 47(1): 312-314, doi: 10.2466/ pms.1978.47.1.312, indexed in Pubmed: 704257.

37. Van Wijk $\mathrm{CH}$. Comparing personality traits of navy divers, navy non-divers, and civilian sport divers. SPUMS J. 2002; 32(1): 2-8.

38. Colvard DF, Colvard LY. A study of panic in creational scuba divers. The Undersea Journal. 2003; 1Q: 40-44.

39. Morgan WP. Anxiety and panic in recreational scuba divers. Sports Med. 1995; 20(6): 398-421, doi: 10.2165/00007256199520060-00005, indexed in Pubmed: 8614760.
40. Van Wijk $\mathrm{CH}$. Personality and behavioural outcomes in diving: current status and recommendations for future research. Diving Hyperb Med. 2017; 47(4): 248-252, doi: 10.28920/dhm47.4.248-252, indexed in Pubmed: 29241235.

41. Carver C, Connor-Smith J. Personality and coping. Annu Rev Psychol. 2010; 61(1): 679-704, doi: 10.1146/annurev. psych.093008.100352.

42. Raglin S, Stegner J. Psychobiological aspects of panic in SCBA and SCUBA. Int J Sport Exerc Psychol. 2005; 4: 446-454.

43. Van Wijk $\mathrm{CH}$, Fourie M. The appropriateness of using the self-directed search questionnaire in developing countries: a pilot study with South African navy divers. Open J Soc Sci. 2017; 5: 60-69, doi: 10.4236/jss.2017.52007. 